\title{
Developing conceptual understanding and procedural fluency for junior high school students through model-facilitated learning (MFL)
}

\author{
Laswadi $^{*}$, Yaya S. Kusumah², Sutawanir Darwis ${ }^{2}$, Jarnawi D. Afgani ${ }^{2}$ \\ ${ }^{1}$ State Islamic Higher Institution of Kerinci, Jambi, Indonesia \\ 2 Indonesia University of Education, Bandung, Indonesia \\ For correspondence: laswadi81@gmail.com
}

\begin{abstract}
Conceptual understanding (CU) and procedural fluency (PF) are two important mathematical competencies required by students. CU helps students organizing their knowledge into a coherent whole, and PF helps them to find the right solution of a problem. In order to enhance CU and PF, students need learning experiences in constructing knowledge and procedures. One of learning approaches which supports CU and PF enhancement is Model-Facilitated Learning (MFL). In MFL, students are given opportunities to build their knowledge and construct their own procedure through exploration with a virtual model. This study was an experiment based on pretest-posttest control group aiming to examine the influence of Model-Facilitated Learning on students' achievement and enhancement of CU and PF. The research subjects were 55 students of grade VII State Junior High School (SJHS) 19 Kerinci, Jambi Province. The results showed that the students who learned mathematics under Model-Facilitated Learning (MFL) had higher CU and PF than the students who received Conventional Learning (CL). Furthermore, the result showed that the students who learned by using MFL had higher enhancement of CU and PF than the students who received Conventional Learning (CL).
\end{abstract}

Keywords: Model-Facilitated Learning, Virtual Model, Conceptual Understanding, Procedural Fluency

\section{Introduction}

Conceptual Understanding (CU) and Procedural Fluency (PF) are two important objectives of mathematics learning at schools. These two competencies are part of mathematics graduation standard indicated in Permendiknas No. 23, year 2006. Additionally, CU and PF are stated as two of five brands of mathematical proficiency by Kilpatrick et al. (2001). According to them, CU and PF are needed by students for learning mathematics succesfully. CU enables students to learn new ideas by connecting those ideas to what they already know. This connection helps them to remember, use, and reconstruct those ideas when they need it. Moreover, students need PF to support their CU, as students with good PF can gain their insight in mathematics concepts and PF can be powerful tool for completing routine tasks.

Students' CU and PF in Indonesia are low. TIMSS' result, year 2011, shows that there were only 20\% of Indonesian students who had right answer for a question which demands CU ability (Mullis, 2012). In addition, the TIMSS' result revealed that there were only $28 \%$ of Indonesian students who had right answer for a question which demands PF ability. These facts indicate that majority of Indonesian students' CU and PF need to be increased.

According to Kilpatrick et al. (2001), in order to build CU and PF, students must have learning experience that provides them with connected mathematical ideas. MFL is one of learning approaches which supports students to explore and elaborate the relationship between one concept and the other 
(Milrad et al., 2003). MFL provides the opportunity for students to understand concepts through exploring activity under computer-based model. Further, in MFL students build their own rules and formula based on their conceptual understanding which will be used for solving problems.

In order to enhance CU and PF, Model-Facilitated Learning (MFL) approach was applied in the mathematics class of grade VII, SJHS 19 Kerinci, academic year 2013/2014. The students' CU and PF enhancement were analyzed. Two goals are discussed in this study. The first goal was to know whether MFL approach is better than CL in enhancing students' CU. The second goal was to know whether MFL approach is better than CL in enhancing students' PF. Both first and second goals were observed based on school levels (upper, middle, lower), mathematical prior knowledge levels (high, middle, low), and overal students.

\section{Conceptual Understanding (CU)}

$\mathrm{CU}$ is one of mathematical abilities that helps students to organize their knowledges. Kilpatrick et al. (2001) stated that CU is an understanding of mathematical ideas as an integrated and functional system. Similarly, Danley (2008) argued that understanding mathematics is not only knowledge about unrelated concepts, but also ability to explain the relationship among them. Thus, students with CU could organize their knowledges and explain them as a coherent system.

There are several abilities which are owned by a student with CU. Kilpatrick et al. (2001) stated that students with CU are able to use their mathematical concepts knowledge for explaining new mathematical concepts. This ability helps students in expanding their knowledge. Moreover, Kilpatrick et al. (2001) said that students with CU are able to use several representations and communicate their ideas. In addition, students with $\mathrm{CU}$ are able to choose a representation that suitable for a specific situation. This ability helps students for communicating their ideas efficiently and effectively.

Three indicators were used to measure students' $\mathrm{CU}$ in this study:

1. Being able to connect mathematical concepts to another one.

2. Being able to represent mathematical situation by a variety of ways.

3. Knowing about the most suitable representation for specific situations.

\section{Procedural Fluency}

According to Kilpatrick et al. (2001), procedural fluency consists of knowledge of procedures, appropriate time and way to use them; and skill in carrying out the procedures flexibly, accurately, and efficiently. Knowledge of a procedure refers to knowledge of its origin, algorithm, and usefulness. Students with PF are not only know about a procedure but also know how to apply the procedure for solving problems. Moreover, student's with PF know informations those are needed to apply a procedure. In addition, students with PF are able to apply the algorithm flexibly. This means that they are able to manipulate a procedure in order to find the right solution for a problem.

$\mathrm{PF}$ is not only involving remembering activity, but also involving thinking process. Thinking process is an important part of PF because it will support students' CU as a basis of procedures (Hiebert, 1999). Thinking process helps students to decide what procedure that they need in solving a problem. Moreover, students with PF can invent their own efficient procedures through thinking process (Bahr and Garcia, 2010).

This study used three indicators to measure students' PF:

1. Knowing about procedures.

2. Knowing about when and how to use the procedure correctly.

3. Being able to use procedures effectively and accurately. 


\section{Model-Facilitated Learning}

According to Milrad et al. (2003), model-facilitated learning (MFL) is the realization of cognitive flexibility theory (CFT). CFT is a theory which was stated by an educational psychologist, Rand J. Spiro. CFT says that students can not have perfect understanding about a domain before they have an opportunity to see a representation of the domain in variety cases (Borsook, 1997). Therefore, students need a representation of a concept that enables them to explore the concept in varying ways and perspectives.

In order to help students exploring a concept in varying ways and perspectives, MFL gives students a virtual model of the concept. As stated by Jong an Joolingen (2007), MFL use computer technology to create a learning environment by providing models of concrete things. Those models are more dynamic and easier to modify than the concrete one. Way and Beardon (2003) posited that computerbased model is an interactive and dynamic learning tool for students. In addition, to make a virtual model needs less materials and less time. Therefore, making a virtual model is more efficient than concrete one.

Milrad et al. (2003) posited three learning steps in MFL approach.

1. Problem-orientation. At this stage, students are given a problem situation with a typical subject and asked to resolve the issue. Students explore a virtual model to get into the learning subject.

2. Inquiry-exploration. Students are challenged to explore a complex topic and asked to identify and elaborate on the relationship causality and important structures. At this stage, students use the model to understand a concept structure.

3. Policy-development. Students are asked to develop rules and heuristics and make a decision or conclusion. The conclusion that is produced are standard rules or models.

\section{Research Methodology}

This study was a quasi-experimental research since it employed treatment manipulation and used existing groups of students as research samples. This study used two groups: experiment group and control group. The experiment group was treated with Model-Facilitated Learning (MFL) and the control group was given Conventional Learning (CL). Both experiment and control group were given prior mathematical knowledge test (PMKT). The PMKT consits of algebra, geometry, and social arithmetic problems. The results of the PMKT are used to classify students into three PMK's level ( high, middle, and low). The research design is described as follows:

$\mathrm{O} \quad \mathrm{X} \quad \mathrm{O}$

O O (Ruseffendi, 1994)

The population of this study was students of State Junior High School (SJHS) 19 Kerinci, Jambi Province. The samples were 55 students (28 students in experiment group and 27 students in control group). Before implementing the treatment, both groups were given pretest $(\mathrm{O})$ on $\mathrm{CU}$ and $\mathrm{PF}$, and after administering the treatment, both groups were given postest $(\mathrm{O})$ on $\mathrm{CU}$ and $\mathrm{PF}$.

\section{Results and Discuss}

Description of CU and PF Pretest

Data of Students' CU and PF pretest is described in Table 1 as follows:

Table 1. Students' CU and PF Pretest Scores Based on PMK

\begin{tabular}{|c|c|c|c|c|c|}
\hline \multirow{2}{*}{ Ability } & \multirow{2}{*}{ PMK Level } & \multirow{2}{*}{ Type of Learning } & \multicolumn{3}{|c|}{ Score } \\
\hline & & & Mean & $\mathrm{s}$ & $\mathrm{n}$ \\
\hline \multirow{4}{*}{$\mathrm{CU}$} & \multirow{2}{*}{ High } & MFL & 3.17 & 1.17 & 6 \\
\hline & & $\mathrm{CL}$ & 3.60 & 0.55 & 5 \\
\hline & \multirow{2}{*}{ Middle } & MFL & 2.47 & 1.01 & 17 \\
\hline & & $\mathrm{CL}$ & 2.44 & 1.03 & 16 \\
\hline
\end{tabular}




\begin{tabular}{|c|c|c|c|c|c|}
\hline & \multirow{2}{*}{ Low } & MFL & 2.20 & 1.48 & 5 \\
\hline & & $\mathrm{CL}$ & 2.17 & 1.47 & 6 \\
\hline & \multirow{2}{*}{ All } & MFL & 2.57 & 1.14 & 28 \\
\hline & & $\mathrm{CL}$ & 2.59 & 1.15 & 27 \\
\hline \multirow{8}{*}{ PF } & \multirow{2}{*}{ High } & MFL & 1.33 & 0.82 & 6 \\
\hline & & CL & 1.60 & 0.55 & 5 \\
\hline & \multirow{2}{*}{ Middle } & MFL & 1.18 & 0.64 & 17 \\
\hline & & CL & 1.12 & 0.72 & 16 \\
\hline & \multirow{2}{*}{ Low } & MFL & 1.00 & 1.00 & 5 \\
\hline & & CL & 1.00 & 0.89 & 6 \\
\hline & \multirow{2}{*}{ All } & MFL & 1.18 & 0.72 & 28 \\
\hline & & CL & 1.18 & 0.74 & 27 \\
\hline
\end{tabular}

Note: Maximum score for $\mathrm{CU}$ is 9 and maximum score PF is 5

Table 1 shows CU and PF pretest result. It can be seen that the overall students of both MFL group and conventional group have an equal CU and PF mean score. However, based on the level of PMK, there are relatively mean secores difference among the groups. The students who received MFL at the high PMK level got lower mean score on both CU and PF than the students who received CL. In contrast, the students who received MFL at the middle PMK level got higher mean score on both CU and PF than students who received CL. At the low level, the students who received MFL got higher mean score on $\mathrm{CU}$ than the students who received $\mathrm{CL}$, but the overall students have an equal mean score on PF.

In order to understand the initial condition of the groups, further examine was held toward CU and PF pretest score. The score were examined by using statistical test i.e. equal mean test as described in the following table.

Table 2. Equal Mean Tests of Students' CU and PF Pretest Score based on PMK

\begin{tabular}{|c|c|c|c|c|c|}
\hline Ability & $\begin{array}{l}\text { PMK } \\
\text { Level }\end{array}$ & Type of Learning & Test Statistic & P-Value & Decision \\
\hline \multirow{4}{*}{$\mathrm{CU}$} & High & MFL $\times$ CL & $t=-0.76$ & 0.47 & \multirow{4}{*}{ Accept $\mathrm{H}_{0}$} \\
\hline & Middle & $\mathrm{MFL} \times \mathrm{CL}$ & $t=0.09$ & 0.93 & \\
\hline & Low & $\mathrm{MFL} \times \mathrm{CL}$ & $t=0.04$ & 0.55 & \\
\hline & All & MFL $\times$ CL & $\begin{array}{c}\text { Mann-Whitney U } \\
(Z=-0.09)\end{array}$ & 0.93 & \\
\hline \multirow{4}{*}{ PF } & High & MFL $\times$ CL & $\begin{array}{c}\text { Mann-Whitney U } \\
(\mathrm{Z}=-0.51)\end{array}$ & 0.61 & \multirow{4}{*}{ Accept $\mathrm{H}_{0}$} \\
\hline & Middle & $\mathrm{MFL} \times \mathrm{CL}$ & $\begin{array}{c}\text { Mann-Whitney U } \\
(Z=-0.18)\end{array}$ & 0.86 & \\
\hline & Low & $\mathrm{MFL} \times \mathrm{CL}$ & $t=1.00$ & 1.00 & \\
\hline & All & MFL $\times C L$ & $\begin{array}{c}\text { Mann-Whitney U } \\
(\mathrm{Z}=-0.04)\end{array}$ & 0.96 & \\
\hline
\end{tabular}

$\mathrm{H}_{0}$ : There is no difference mean on $\mathrm{CU}$ and PF Pretest Score

Table 2 shows the test $p$-value of each PMK levels. It can be seen that all of $p$-value are greater than $a=0,05$. Thus, $\mathrm{HO}$ is accepted which is mean that there is no significant difference on CU and PF pretest mean score among three PMK levels (high, middle and low) and overall students. The result confirms that the research subject has the same initial CU and PF ability.

Description of Posttest Score and Normalized Gain in CU and PF

Table 3 provides an overview of student CU and PF posttest score and normalized gain. The data consists of posttest score mean and normalized gain mean based on PMK levels. 
Table3. Description of Posttest Score and Normalized Gain of students' CU and PF

\begin{tabular}{|c|c|c|c|c|c|c|}
\hline \multirow{2}{*}{ Ability } & \multirow{2}{*}{$\begin{array}{l}\text { PMK } \\
\text { Level }\end{array}$} & \multirow{2}{*}{$\begin{array}{l}\text { Type of } \\
\text { Learning }\end{array}$} & \multicolumn{2}{|c|}{ Posttest Score } & \multicolumn{2}{|c|}{ Normalized Gain } \\
\hline & & & Mean & $\mathrm{s}$ & Mean & $\mathrm{s}$ \\
\hline \multirow{8}{*}{$\mathrm{CU}$} & \multirow{2}{*}{ High } & MFL & 8.17 & 0.75 & 0.87 & 0.11 \\
\hline & & $\mathrm{CL}$ & 7.40 & 0.89 & 0.71 & 0.13 \\
\hline & \multirow{2}{*}{ Middle } & MFL & 6.59 & 1.23 & 0.65 & 0.14 \\
\hline & & $\mathrm{CL}$ & 5.75 & 1.00 & 0.51 & 0.10 \\
\hline & \multirow{2}{*}{ Low } & MFL & 6.60 & 1.82 & 0.68 & 0.21 \\
\hline & & $\mathrm{CL}$ & 5.17 & 1.94 & 0.46 & 0.21 \\
\hline & \multirow{2}{*}{ All } & MFL & 6.93 & 1.38 & 0.70 & 0.17 \\
\hline & & CL & 5.92 & 1.41 & 0.54 & 0.16 \\
\hline \multirow{8}{*}{ PF } & \multirow{2}{*}{ High } & MFL & 4.17 & 0.41 & 0.77 & 0.12 \\
\hline & & $\mathrm{CL}$ & 3.40 & 1.14 & 0.55 & 0.30 \\
\hline & \multirow{2}{*}{ Middle } & MFL & 3.76 & 0.90 & 0.70 & 0.20 \\
\hline & & $\mathrm{CL}$ & 2.56 & 1.03 & 0.39 & 0.18 \\
\hline & \multirow{2}{*}{ Low } & MFL & 3.60 & 0.89 & 0.67 & 0.16 \\
\hline & & $\mathrm{CL}$ & 2.67 & 1.03 & 0.43 & 0.16 \\
\hline & \multirow{2}{*}{ All } & MFL & 3.82 & 0.82 & 0.71 & 0.18 \\
\hline & & CL & 2.74 & 1.06 & 0.43 & 0.20 \\
\hline
\end{tabular}

Note: Maximum score for $\mathrm{CU}$ is 9 and maximum score for PF is 5

According to Table 3, the posttest mean score of the CU and PF which is gained by the students of MFL group is higher than CL group based on PMK levels and overall students. Therefore, it can be said that MFL has succeeded in helping students to achieve CU and PF. Furthermore, the table shows that higher enhancement of CU and PF occurred in MFL classes at all PMK levels and overall students. Thus it can be concluded that MFL is appropriate to all PMK levels. However, this tendency needs further study by using inferential statistics test. The results of the tests are showed in Table 4 and Table 5 below.

Table 4. Equal Mean Tests of Students' CU and PF Posttest Score based on PMK

\begin{tabular}{|c|c|c|c|c|c|}
\hline Ability & $\begin{array}{l}\text { PMK } \\
\text { Level }\end{array}$ & $\begin{array}{c}\text { Type of } \\
\text { Learning }\end{array}$ & Test Statistic & P-Value & Decision \\
\hline \multirow{4}{*}{$\mathrm{CU}$} & High & $\mathrm{MFL} \times \mathrm{CL}$ & $t=1.55$ & 0.16 & Accept $\mathrm{H}_{0}$ \\
\hline & Middle & $\mathrm{MFL} \times \mathrm{CL}$ & $t=2.14$ & 0.04 & Reject $\mathrm{H}_{0}$ \\
\hline & Low & $\mathrm{MFL} \times \mathrm{CL}$ & $t=1.26$ & 0.24 & Accept $\mathrm{H}_{0}$ \\
\hline & All & $\mathrm{MFL} \times \mathrm{CL}$ & $\begin{array}{c}\text { Mann-Whitney U } \\
\quad(\mathrm{Z}=-2.09)\end{array}$ & 0.04 & Reject $\mathrm{H}_{0}$ \\
\hline \multirow{4}{*}{$\mathrm{PF}$} & High & $\mathrm{MFL} \times \mathrm{CL}$ & $\begin{array}{c}\text { Mann-Whitney U } \\
(Z=-1.40)\end{array}$ & 0.16 & Accept $\mathrm{H}_{0}$ \\
\hline & Middle & $\mathrm{MFL} \times \mathrm{CL}$ & $\begin{array}{c}\text { Mann-Whitney U } \\
\quad(\mathrm{Z}=-2.99)\end{array}$ & 0.03 & Reject $\mathrm{H}_{0}$ \\
\hline & Low & $\mathrm{MFL} \times \mathrm{CL}$ & $\begin{array}{c}\text { Mann-Whitney U } \\
\quad(\mathrm{Z}=-1.39)\end{array}$ & 0.16 & Accept $\mathrm{H}_{0}$ \\
\hline & All & $\mathrm{MFL} \times \mathrm{CL}$ & $\begin{array}{c}\text { Mann-Whitney U } \\
\quad(Z=-3.68)\end{array}$ & 0.00 & Reject $\mathrm{H}_{0}$ \\
\hline
\end{tabular}

H0: There is no difference mean on the students' CU and PF posttest score

Table 4 shows the diversity of equal mean test results of students' CU and PF posttest score. Overall students who worked under MFL approach have higher achievement on CU and PF than students worked under CL approach. Furtheremore, it can be seen that there is no difference in students achievement of CU and PF between MFL group and CL group at high and low PMK levels. On the 
other hand, students on middle PMK level who worked under MFL approach have higher achievement on CU and PF than students who worked under CL approach.

Table 5 below peresents equal mean tests of the students' CU and PF Normalized Gain based on PMK levels.

Table 5. Equal Mean Tests of Students' CU and PF Normalized Gain based on PMK

\begin{tabular}{|c|c|c|c|c|c|}
\hline Ability & $\begin{array}{l}\text { PMK } \\
\text { Level }\end{array}$ & $\begin{array}{l}\text { Type of } \\
\text { Learning }\end{array}$ & Test Statistic & P-Value & Decision \\
\hline \multirow{4}{*}{$\mathrm{CU}$} & High & $\mathrm{MFL} \times \mathrm{CL}$ & $\begin{array}{c}\text { Mann-Whitney U } \\
(\mathrm{Z}=-1.88)\end{array}$ & 0.05 & Reject $\mathrm{H}_{0}$ \\
\hline & Middle & $\mathrm{MFL} \times \mathrm{CL}$ & $\begin{array}{c}\text { Mann-Whitney U } \\
(\mathrm{Z}=-2.93)\end{array}$ & 0.00 & Reject $\mathrm{H}_{0}$ \\
\hline & Low & MFL $\times$ CL & $t=1.68$ & 0.13 & Accept $\mathrm{H}_{0}$ \\
\hline & All & MFL $\times C L$ & $\begin{array}{c}\text { Mann-Whitney U } \\
(\mathrm{Z}=-1.59)\end{array}$ & 0.00 & Reject $\mathrm{H}_{0}$ \\
\hline \multirow{4}{*}{ PF } & High & $\mathrm{MFL} \times \mathrm{CL}$ & $t=1.68$ & 0.13 & Accept $\mathrm{H}_{0}$ \\
\hline & Middle & $\mathrm{MFL} \times \mathrm{CL}$ & $\begin{array}{c}\text { Mann-Whitney U } \\
(Z=-3.64)\end{array}$ & 0.00 & Reject $\mathrm{H}_{0}$ \\
\hline & Low & MFL $\times$ CL & $t=2.26$ & 0.05 & Reject $\mathrm{H}_{0}$ \\
\hline & All & MFL $\times C L$ & $\begin{array}{c}\text { Mann-Whitney U } \\
(\mathrm{Z}=-4.51\end{array}$ & 0.00 & Reject $\mathrm{H}_{0}$ \\
\hline
\end{tabular}

H0: There is no difference mean on CU and PF Normalized Gain

According to Table 5, the difference of students CU enhancement between MFL and CL groups occured at higher and middle PMK level and overall students. It can be concluded that students who worked under MFL approach have higher CU enhancement than students who received CL approach at higher and middle PMK level and overall students. However, at low PMK level, there is no CU enhancement difference between students who worked under MFL approach and students who worked under CL approach. In contrast with CU, PF enhancement of students who work under MFL approach is higher than PF enhancement of student who worked under CL approach at middle and low PMK levels and overall students. At high PMK level, there is no PF enhancement difference between students who worked under MFL approach and students who worked under CL approach.

\section{Description of Interactions between IMA and learning treatments}

Picture 1 below is a description of estimate marginal means of CU Enhancement.

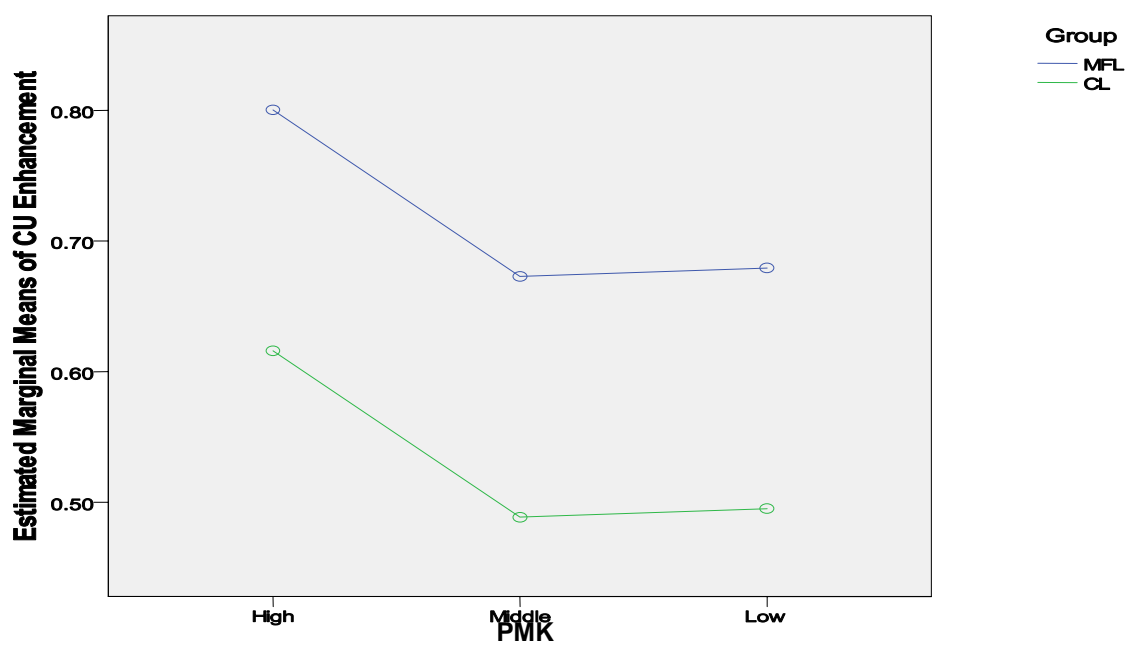

Picture 1. Estimate Marginal Means of students' CU Enhancement 
Picture 1 shows that students who worked under MFL approach have higher CU enhancement than students who worked under CL approach on all PMK levels. Moreover, the picture shows that the differences of CU enhancements between MFL groups and CL groups are almost equal. Thus, it can be said that there is no interaction between PMK and learning treatments in enhancing students' $\mathrm{CU}$.

Picture 2 below provides a description of estimate marginal means of PF Enhancement.

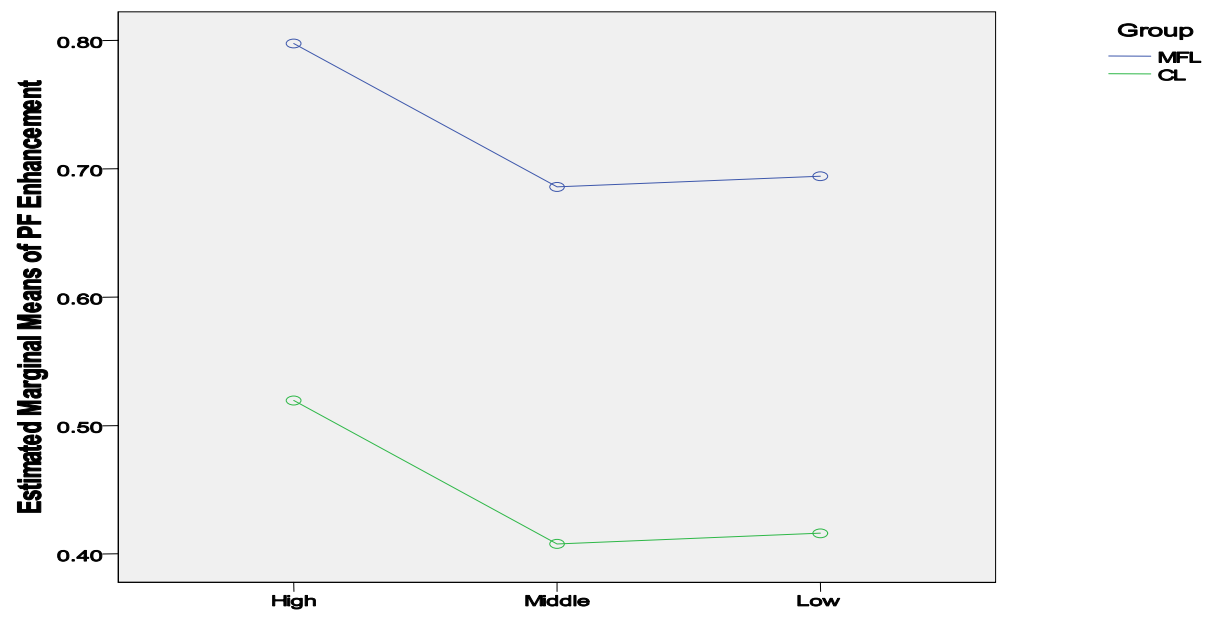

Picture 2. Estimate Marginal Means of PF Enhancement

According to picture 2, the students who studied mathematics with MFL have higher PF enhancement than the students who studied mathematics with CL on all PMK levels. Therefore, it can be said that there is no interaction between PMK and learning treatments in enhancing students' CU.

\section{Discussion}

The findings of this study describe how MFL works on students' CU and PF. The study shows that the students who worked under MFL approach have higher achievement and enhancement on CU and PF significantly. The findings support Samur's (2012) study result. He studied the engagement effects of educational games and virtual manipulatives on mathematics. He found that students who do activities with virtual manipulatives (virtual model) showed significantly a higher engagement than students who do paper-and-pencil drills. In MFL class, students were given virtual models to solve problem that is posed. This activity gives students opportunity to build their CU. This is supported by NCTM (2000) which stated that students must be engaged actively in tasks and experiences which are designed to build their understanding of mathematical ideas.

Furthermore, the findings in this study support NCTM's (2014) statements that students need experiences in integrating concepts and procedures and in building their procedures and strategies. This is in line with the MFL approach. on the third MFL step, students are given opportunity to build their own definitions, rules, models and procedures.

There are no interactions between PMK and learning treatments in enhancing students'PF and students' $\mathrm{CU}$ were founded. However, it can be seen that students who worked under MFL approach on middle PMK level have higher achievement and enhancement of CU and PF than students who received MFL approach significantly. This findings are in line with the theory stated that prior knowledge has strong effects on students' ability to acquire new concepts (Burn, 2007; Gruber et al., 2011). Therefore, the prior knowledge of the students on high PMK level had more contribution to the students' achievement and enhancement of CU and PF than the virtual model of MFL. In contrast, the students on low PMK level need more concrete model to helps them acquire new knowledges. Thus, it can be concluded that PMK-middle students are more succesfully than other PMK levels. 


\section{Conclusion}

Based on the results and analysis, it can be concluded:

1. All of the students worked under MFL have higher achievement and enhancement of CU and PF than the students received CL. Acording to Hake's (1999) normalized gain regions, the mean of $\mathrm{CU}$ enhancement is lay on middle-g region whereas the mean of PF enhancement is lay on highg region.

2. The students with middle PMK level who worked under MFL approach have higher achievement on CU and PF than the students who worked under CL approach. Based on maximum score of $\mathrm{CU}$ and $\mathrm{PF}$, it can be said that the $\mathrm{CU}$ and PF achievement means of the students with middle PMK level who worked under MFL are high.

3. Students who worked under MFL approach have higher CU enhancement than students who worked under CL approach at high PMK level. The enhancement can be categorized into middle level.

4. PF enhancement of students who worked under MFL approach is higher than students who worked under CL approach at low PMK level. The enhancement can be categorized into high level.

\section{References}

Bahr, D.L., and Garcia, L.A. (2010). Elementary Mathematics is Anything but Elementary: Content and Methods from a Developmental Perspective. Belmont: Wadsworth, Cengage Learning.

Borsook, T.K. (1997). Hypermedia: Harbinger of A New Instructional Paradigm. C.R. Dills and A.J. Romiszowski (Ed.). Instructional Development Paradigm (pp.721-741). New Jersey: Educational Technology Education, Inc.

Burns, M. (2007) About Teaching Mathematics A K-8 Resource Third Edition. Sausalito, CA: Math Solutions Publications.

Danley (2008) "Mathematical Proficiency" http://www.havasu.k12.az.us/pdf/staff_articles/math_proficiency.pdf, (accessed November 2013)

Gruber, S.R., McCuddy, M.K., Parisot, X., and Rossi, D. (2011). Moving Beyond Teaching and Learning into a Human Development Paradigm Concepts and an Application. D. Ifenthaler, P. Isaías, J.M. Spector, Kinshuk, and D.G. Sampson (Ed.). Multiple Perspectives on Problem Solving and Learning in the Digital Age (pp.243-256). New York: Springer.

Hake, R. (1999) “Analizing Change/Gain Score” http://www.physics.indiana.edu/ sdi/AnalyzingChange-Gain.pdf, (accessed November 2013)

Hiebert, J. (1999). Relationships between research and the NCTM standards. Journal for Research in Mathematics Education, 30(1), 3-19.

Jong, Td., and Joolingen, W.R. (2007). Model-Facilitated Learning. J.M. Spector, M.D. Merril, J.V. Merrienboer, and M.P. Driscoll (Ed.). Handbook of Research on Educational Communications and Technology (pp.457-468). New York: Taylr and Francis Group LLC.

Killpatrick, J., Swafford, J., and Findell, B. (2001). Adding it up: Helping Children Learn Mathematics. Washington, DC: National Academy Press.

Milrad, M., Spector M., and Davidsen, P. (2003). Model Facilitated Learning. S. Naidu (Ed.) Learning and Teaching with Technology (pp.11-24). London: Taylor \& Francis Group LLC.

NCTM (2000). Principles and Standards for School Mathematics. New York: The National Council of Teachers of Mathematics, Inc.

NCTM (2014) “Procedural Fluency in Mathematics” http:/ / www.nctm.org/about/content.aspx?id=42833, (accessed November 2014)

Puskur Kemendiknas. (2007) “Kajian Kebijakan Kurikulum Mata Pelajaran Matematika” http://puskurbuk.net/web/download/prod2007/50_Kajian\%20Kebijakan\%20Kurikulum\%20Matematika.pdf, (accessed September 2012)

Ruseffendi, E.T. (2005). Dasar-dasar Penelitian Pendidikan dan Bidang Non Eksakta Lainnya. Bandung : Tarsito

Samur, Y. (2012). Measuring Engagement Effects of Educational Games and Virtual Manipulatives on Mathematics. (Unpublished doctoral dissertation). Virginia Polytechnic Institute and State University, Virginia.

Way, J. and Beardon, T. (2003). Digital Technologies + Mathematics Education = Powerful Learning Environments. J. Way and T. Beardon (Ed.). Ict and Primary Mathematics (pp.1-6). Philadelphia: Open University Press. 